\title{
Low dose maintenance treatment with cimetidine in duodenal ulcer: intermediate-term results
}

\author{
K.D. Bardhan, R.F.C. Hinchliffe and K. Bose \\ District General Hospital, Moorgate Road, Rotherham S60 2UD, UK.
}

\begin{abstract}
Summary: Ulcer relapse rates during up to 2 years of prophylactic low-dose maintenance therapy (LDMT) with cimetidine $400 \mathrm{mg}$ at bedtime was examined in 261 patients. Endoscopy was repeated every 6 months if asymptomatic, or whenever symptoms recurred. Relapse was defined as the recurrence of an ulcer crater or erosions or both.

In patients with non-refractory duodenal ulcer (those healed within 3 months) who comprise the majority, their likelihood of relapse at 6, 12, 18 and 24 months was: symptomatic $8 \%, 13 \%, 18 \%, 20 \%$; silent $14 \%, 28 \%, 38 \%, 43 \%$, respectively. In contrast, in patients with refractory ulcer, their symptomatic relapse rates were $36 \%, 45 \%, 46 \%, 48 \%$, and silent $28 \%, 38 \%, 46 \%, 48 \%$ respectively. The outcome of a second course of LDMT was similar to the first. Narrowing the definition of relapse to exclude recurrence of erosions alone but without an ulcer decreased asymptomatic relapse in nonrefractory ulcer patients by about half. No patient had any major side effects.

Thus, LDMT is a safe and effective way of keeping most patients with duodenal ulcer symptom free over 2 years.
\end{abstract}

\section{Introduction}

Low dose maintenance treatment (LDMT) with cimetidine at the standard dose of $400 \mathrm{mg}$ at bedtime following healing of duodenal ulcer, markedly reduces the relapse rate over the next year (Burland et al., 1980; Misiewicz \& Bradbury, 1984), but little is known of the outcome of longer periods of treatment. We therefore present our results of up to 2 years' followup. We have investigated the symptomatic and silent relapse rates and have observed that patients with a refractory duodenal ulcer have a poor outcome.

\section{Patients and methods}

Two hundred and sixty-one patients with duodenal ulcer proven by endoscopy were treated with cimetidine $1 \mathrm{~g} /$ day $(200 \mathrm{mg}$ three times daily after meals and $400 \mathrm{mg}$ at bedtime) till healing was complete as judged by endoscopy which was repeated every 4 to 6 weeks. They were then treated with cimetidine $400 \mathrm{mg}$ at bedtime. Liquid or tablet antacids in small amounts were allowed for relief of mild symptoms. Endoscopy was done within a fortnight if there was a recurrence of pain or heartburn or acid regurgitation; but if asymptomatic a routine endoscopy was done approximately

Correspondence: K.D. Bardhan, D.Phil. (Oxon), F.R.C.P. Accepted: 11 December 1985 every 6 months. Those who had relapsed were retreated with cimetidine $1 \mathrm{~g} /$ day till healed and the process repeated.

The value of maintenance treatment was assessed, albeit historically, by comparing the outcome with that of placebo maintenance in an investigation which immediately preceded the current study (Bardhan et al., 1982). In it, 180 of 248 patients whose duodenal ulcer had healed at one month on cimetidine $1 \mathrm{~g} /$ day, were then maintained on placebo; most relapsed and on re-healing were entered into the current cimetidine maintenance programme.

Healing was defined as the complete disappearance of ulcer(s) and/or erosions and their replacement by intact mucosa which was normal or inflamed. Relapse or recurrence was the re-appearance of ulcer(s) or only erosions, or both. An ulcer was a lesion which had depth whereas erosions were small, yellow (the colour being similar to ulcers) but superficial. A relapse was classified as symptomatic when symptoms had occurred within one month before endoscopy, even if the patient was symptom free at the time of the examination; this was to take into account those with intermittent symptoms. A refractory duodenal ulcer was one that failed to heal on cimetidine $1 \mathrm{~g}$ /day within 3 months (Bardhan, 1984).

The probability of relapse was calculated by standard life table analysis. The outcome of the first and 
second courses of treatment was compared using the generalized Wilcoxon test (Gehan, 1965). This study was part of a wider programme on the long-term treatment of duodenal ulcer and was approved by the Rotherham Health Authority Ethical Committee.

\section{Results}

\section{Outcome of the first course of treatment}

The probability of relapse increased with time but was highest during the first year of treatment. This was particularly so for symptomatic relapse, the cumulative probability was $20 \%$ at 1 year and only a further $5 \%$ (total $25 \%$ ) at 2 years. Silent relapse was more common, the corresponding figures being $32 \%$ and $49 \%$. No patient had haemorrhage or perforation at the time of relapse (Figure 1).

\section{Outcome of the second course of maintenance treatment}

A second course of maintenance treatment was given to 137 patients. The relapse rate during the second course was higher than during the first but was not significantly different. This is despite the bias, which may have occurred against patients on repeated treatment for having relapsed once they may have more aggressive disease. Again, no patient developed any ulcer complications at the time of relapse. Therefore, a second course of maintenance treatment is not necessarily more likely to fail than the first course (Figure 2).

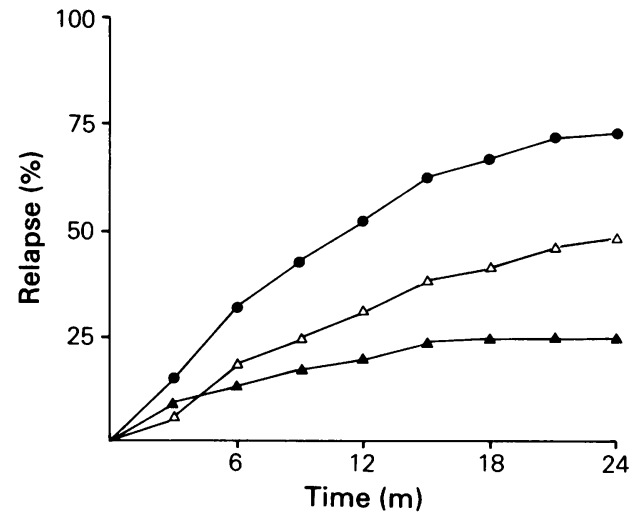

Figure 1 The probability of relapse in the 261 patients with healed duodenal ulcer during the first course of low dose maintenance treatment with cimetidine $400 \mathrm{mg}$ at bedtime: symptomatic, silent and symptomatic plus silent (total) relapse rates: total, $\Delta$ silent, $\Delta$ symptomatic.

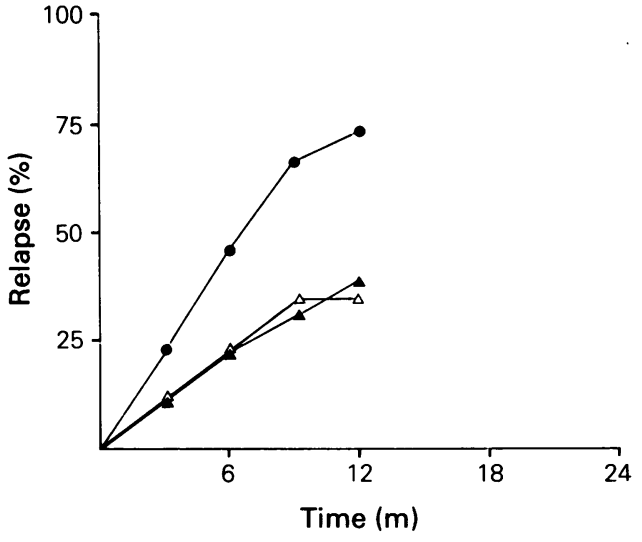

Figure 2 The probability of relapse during the second course of low dose maintenance treatment with cimetidine $400 \mathrm{mg}$ at bedtime: symptomatic, silent and total relapse: total, $\Delta$ silent, $\Delta$ symptomatic.

\section{Refractory versus non-refractory duodenal ulcer}

Refractory duodenal ulcer (61 patients) was associated with a high and early probability of relapse; symptomatic $45 \%$ at 1 year and $48 \%$ at 2 years; silent $38 \%$ and $48 \%$ respectively. In contrast, relapse in those with non-refractory duodenal ulcer (200 patients) was likely to be both less frequent and slower: at 1 year and5 2 years symptomatic $13 \%$ and $20 \%$, silent $28 \%$ and $43 \%$ respectively (Figure 3 ).

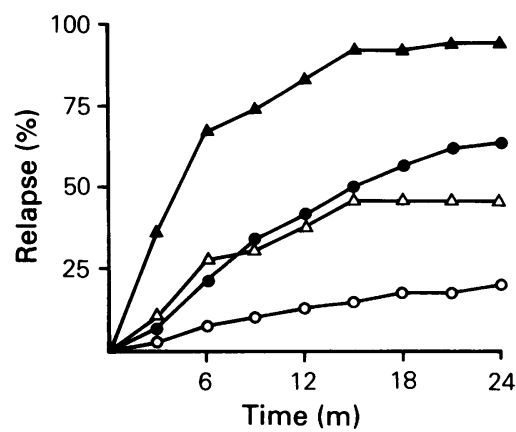

Figure 3 The probability of relapse during the first course of low dose maintenance treatment with cimetidine $400 \mathrm{mg}$ at bedtime: refractory $(n=61)$ versus non-refractory $(n=200)$ duodenal ulcer. Symptomatic and total (symptomatic plus silent) relapse rates: $\Delta$ refractory total; non-refractory total; $\Delta$ refractory symptomatic; $\bigcirc$ non-refractory symptomatic. 
Table I The relation between the type of lesion at relapse and symptoms based on 137 patients who relapsed

\begin{tabular}{|c|c|c|c|c|c|}
\hline $\begin{array}{l}\text { Clinical state at } \\
\text { time of relapse }\end{array}$ & $\begin{array}{c}\text { Type of ulcer } \\
\text { patient }\end{array}$ & $\begin{aligned} & \text { Ulcer } \\
& \pm \text { erosions }\end{aligned}$ & Erosion & ns only & Total \\
\hline Silent & $\begin{array}{c}\text { Non-refractory } \\
\text { Refractory }\end{array}$ & $\left.\begin{array}{l}28(20 \%) \\
16(21 \%)\end{array}\right\} 44(32 \%)$ & $\left.\begin{array}{cc}29 & (21 \%) \\
10 & (7 \%)\end{array}\right\}$ & $39(29 \%)$ & $83(61 \%)$ \\
\hline Symptomatic & $\begin{array}{c}\text { Non-refractory } \\
\text { Refractory }\end{array}$ & $\left.\begin{array}{l}23(17 \%) \\
21(15 \%)\end{array}\right\} 44(32 \%)$ & $\left.\begin{array}{ll}7 & (5 \%) \\
3 & (2 \%)\end{array}\right\}$ & $10(7 \%)$ & $54(39 \%)$ \\
\hline
\end{tabular}

\section{The relation between lesions and symptoms}

The absence of symptoms did not necessarily indicate an absence of disease; if there was a recurrence, the lesion was as likely to be an ulcer as erosions. In contrast, if there were symptoms, then there was a five times greater chance of the lesion being an ulcer (with or without associated erosions) than erosions alone (Table I).

\section{The effect of the type of lesions on the calculation of relapse rates}

The definition of ulcer recurrence had an effect on calculating the relapse rate. When relapse was redefined as the recurrence of an ulcer crater with or without associated erosions, i.e. excluding those patients who had erosions alone, the silent relapse rates were lower both in patients with refractory and with non-refractory ulcers, and this in turn reduced the total relapse rates (Table II).

\section{Patients with erosions alone}

The likelihood to relapse with only erosions (i.e. no associated ulcer) steadily increased with time but the majority of patients were asymptomatic. After 2 years, of the 61 patients with refractory duodenal ulcer, 13 $(21 \%)$ developed erosions alone but with symptoms in 3 patients (i.e. $5 \%$ of the 61 ). Amongst 200 patients with non-refractory duodenal ulcer, $36(18 \%)$ developed erosions but only 7 patients $(3 \%$ of the 200$)$ were symptomatic.

\section{Value of maintenance treatment}

The likelihood of relapse on placebo at 1 and at 2 years was respectively symptomatic $73 \%$ and $82 \%$, silent $11 \%$ and $12 \%$. In contrast on cimetidine $400 \mathrm{mg}$ nightly relapse was less, markedly so for symptomatic recurrence $(P<0.001$ for both total and symptomatic relapse). On cimetidine the chance of relapse at 1 and at 2 years was, respectively, reduced to: symptomatic $20 \%$ and $25 \%$, silent $32 \%$ and $49 \%$ (Figure 4 ).

Table II The effect of the type of lesions on the calculation of relapse rates

\begin{tabular}{|c|c|c|c|c|c|c|c|c|}
\hline & \multicolumn{8}{|c|}{ Cumulative relapse* at (months): } \\
\hline & \multicolumn{2}{|c|}{6} & \multicolumn{2}{|c|}{12} & \multicolumn{2}{|c|}{18} & \multicolumn{2}{|c|}{24} \\
\hline & $n$ & $\%$ & $n$ & $\%$ & $n$ & $\%$ & $n$ & $\%$ \\
\hline \multicolumn{9}{|l|}{ All patients } \\
\hline Total & 54 & $23 \%$ & 75 & $40 \%$ & 85 & $54 \%$ & 88 & $64 \%$ \\
\hline Silent & 20 & $9 \%$ & 34 & $18 \%$ & 43 & $28 \%$ & 44 & $32 \%$ \\
\hline Symptomatic & 34 & $14 \%$ & 41 & $22 \%$ & 42 & $26 \%$ & 44 & $32 \%$ \\
\hline \multicolumn{9}{|c|}{ Non-refractory ulcer } \\
\hline Total & 27 & $15 \%$ & 35 & $29 \%$ & 38 & $42 \%$ & 39 & $50 \%$ \\
\hline Silent & 8 & $4 \%$ & 12 & $10 \%$ & 15 & $16 \%$ & 16 & $20 \%$ \\
\hline Symptomatic & 19 & $11 \%$ & 23 & $19 \%$ & 23 & $26 \%$ & 23 & $30 \%$ \\
\hline \multicolumn{9}{|l|}{ Refractory ulcer } \\
\hline Total & 27 & $50 \%$ & 40 & $73 \%$ & 47 & $85 \%$ & 49 & $95 \%$ \\
\hline Silent & 12 & $22 \%$ & 22 & $40 \%$ & 28 & $51 \%$ & 28 & $55 \%$ \\
\hline Symptomatic & 15 & $28 \%$ & 18 & $33 \%$ & 19 & $34 \%$ & 21 & $40 \%$ \\
\hline
\end{tabular}

* Relapse is now re-defined as the recurrence of ulcer(s) with or without erosions, i.e. excluding patients who had only erosions. By re-definition 88 patients were classed as having relapsed. 


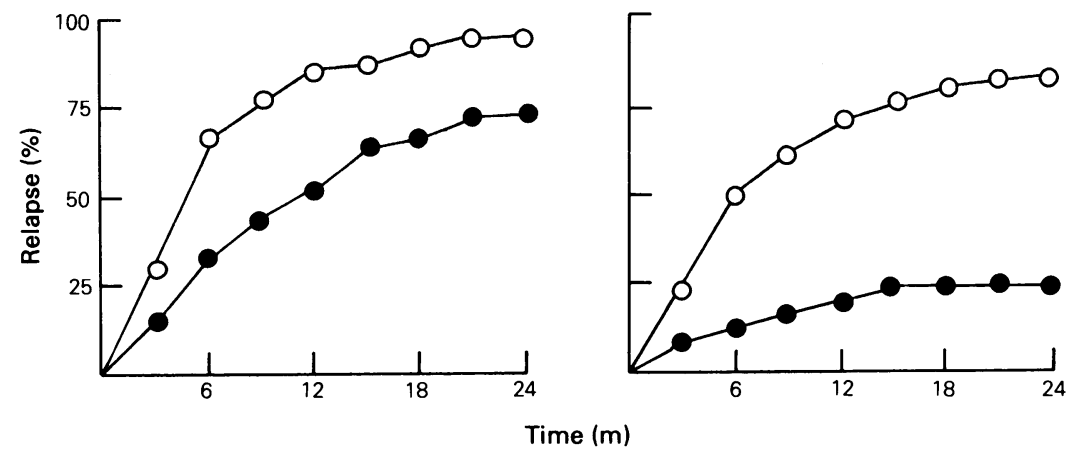

Figure 4 The probability of relapse during maintenance treatment on placebo $(O), n=180$, compared with low dose maintenance treatment on cimetidine $(O), n=261$. The left-hand figure shows silent plus symptomatic (total) and the right, symptomatic only.

\section{Adverse events}

Adverse events were rare and no patient had to be withdrawn. One patient had breast tenderness which cleared spontaneously despite continued treatment; and another had arthralgia on healing doses (1g) of cimetidine with marked improvement when the dose was reduced to $400 \mathrm{mg}$ at bedtime. These two patients were reported earlier (Bardhan et al., 1982). No clinically significant drug interactions were recognized.

\section{Discussion}

In this study we found that in patients with nonrefractory duodenal ulcer, who form the vast majority of ulcer patients, the symptomatic relapse rate was low and that the chance of relapse diminished after the first year: $13 \%$ at 1 year and $20 \%$ at 2 years. On re-healing and on further maintenance treatment, the pattern is likely to repeat itself. This is despite the fact that as this group of patients have relapsed once already, a poorer outcome might have been expected. There are only few reports of maintenance treatment with cimetidine or ranitidine for longer than one year with which to compare our own, but other investigators, like ourselves, have observed that the relapse rate decreses markedly after the first year (Bianchi Porro et al., 1980; Bianchi Porro, 1982; Kratochvil \& Brandstatter, 1983; Ström et al., 1984; Gray et al., 1982; Walan et al., 1985; Schutz, 1983; Boyd et al., 1984).

Three conclusions follow. First, those likely to develop a symptomatic relapse during maintenance treatment will commonly do so in the first year. Second, as a subsequent course of maintenance treatment is likely to be as effective as the first, a single relapse without complications is not necessarily an indication for abandoning such treatment. Third, there is reason to be cautiously optimistic that maintenance treatment will remain effective in the longterm and that it probably prevents relapse rather than merely postpone it.

Smoking (Sontag et al., 1984; McCarthy, 1984; Boyd et al., 1984), a long ulcer history (Gough et al., 1984) and pre-pyloric ulcers (Ström et al., 1984) have been reported to increase relapse rates during maintenance treatment. To these factors we add refractory duodenal ulcer, which in this centre was almost invariably associated with relapse.

Most studies of maintenance treatment with cimetidine are of one year's duration (or less); we have therefore compared our relapse rates at one year with these results. The total (i.e. symptomatic plus silent) and symptomatic relapse rates we observed of $52 \%$ and $20 \%$ respectively are within the range found by others, but our silent relapse rate of $32 \%$ is higher. Thus, in 14 studies, the relapse at one year on average was: total $34 \%$ (range $13 \%$ to $65 \%$ ); symptomatic $11 \%$ (range $8 \%$ to $32 \%$ ); silent $8 \%$ (range $8 \%$ to $15 \%$ ) (Misiewicz \& Bradbury, 1984). Two patient groups contribute to our higher than average relapse rates: patients with refractory ulcer and patients who relapsed with erosions alone. When they are excluded, thereby making the remainder of the patients more comparable with those reported in other studies, the relapse rate fell: total $29 \%$, symptomatic $19 \%$, silent $10 \%$. One possible explanation for the higher than usual incidence of duodenal erosions alone (i.e. without an ulcer) seen in our patients with non-refractory ulcer, is that they may have more severe disease than apparently similar patients reported in the literature. Thus our patients were put on maintenance treatment only after they had two or more relapses during placebo treatment (Bardhan et al., 1982) or during intermittent treatment (Bardhan, 1980). Patient selec- 
tion and definition of recurrence can therefore substantially influence relapse rates.

For patient management, the most useful information on the outcome of maintenance treatment is the symptomatic relapse rate. Therefore, it is arguable whether silent relapse or recurrence of erosions alone should be included in calculating the relapse rate (which as a result is considerably increased); indeed most investigators do not. But we have used these indices partly to give a more complete picture of the outcome of treatment and partly because we view these events as markers of disease reactivation although clinically they may not be important.

None of our patients who relapsed, with or without symptoms, developed complications. We did not monitor the biochemistry of our patients but clinically none suffered any major adverse reaction on maintenance cimetidine treatment.

As a result of our findings, we no longer routinely use low dose maintenance treatment with cimetidine $400 \mathrm{mg}$ at bedtime in patients with refractory duodenal ulcer; their medical management remains unsatisfactory and although several come to surgery

\section{References}

BARDHAN, K.D. (1980). Intermittent treatment of duodenal ulcer with cimetidine. British Medical Journal, 281, 20.

BARDHAN, K.D., COLE, D.S., HAWKINS, B.W. \& FRANKS, C.R. (1982). Does treatment with cimetidine extend beyond initial healing of duodenal ulcer reduce the subsequent relapse rate? British Medical Journal, 284, 621.

BARDHAN, K.D. (1984). Refractory duodenal ulcer. Gut, 25, 711.

BIANCHI PORRO, G. (1982). Long-term management of recurrent duodenal ulceration. In Experience and innovation. $A$ review and preview of $\mathrm{H}_{2}$ receptor antagonists. Program and Abstracts. World Congress of Gastroenterology, June 15, Stockholm, Sweden. Smith Kline \& French International, 1982: 6.

BIANCHI PORRO, G., BURLAND, W.L., HAWKINS, B.W. \& PETRILLO, M. (1980). Long-term treatment of duodenal ulcer with cimetidine: a review. In Further experience with $\mathrm{H}_{2}$ receptor antagonists in peptic ulcer disease and progress in histamine research. Torsoli, A., Lucchelli, P.E., Brimblecombe, R.W. (eds). European Symposium, Oct 18-20, 1979, Capri, Italy. p.91. Excerpta Medica: Amsterdam.

BOYD, E.J.S., WILSON, J.A. \& WORMSLEY, K.G. (1984). Safety of ranitidine maintenance treatment of duodenal ulcer. Scandinavian Journal of Gastroenterology, 19, 394.

BOYD, E.J.S., WILSON, J.A. \& WORMSLEY, K.G. (1984). Recurrent ulcer disease. In Ranitidine: therapeutic advances. Misiewicz, J.J. \& Wood, J.R. (eds). p.14. Excerpta Medica: Amsterdam.

BURLAND, W.L., HAWKINS, B.W. \& BERESFORD, J. (1980). Cimetidine treatment for the prevention of recurrence of duodenal ulcer: an international collaborative study. Postgraduate Medical Journal, 56, 173.

GEHAN, E.A. (1965). The generalised Wilcoxon test for the results of operation are, in our experience, often poor (Bardhan, 1984). In the non-refractory group of ulcer patients, such treatment does not necessarily suppress the disease; but it is an effective way of keeping the majority symptom-free both simply and with safety, and allows most patients to lead normal lives.

\section{Acknowledgements}

The Day Ward and the endoscopy nursing and clerical staff coped with increasing pressure; Dr C.D. Holdsworth provided valuable comments; the Medical Illustrations Departments at the Royal Hallamshire Hospital, Sheffield and at this hospital, provided the figures; Beverley Mason typed the manuscripts; the Rotherham Health Authority continues to support such studies. We are indebted to all.

KDB is deeply grateful for the opportunities, training and guidance he has received from Dr C. Derek Holdsworth, Consultant Physician at the Royal Hallamshire Hospital, Sheffield, and as a token of his appreciation dedicates this paper to him. comparing arbitrarily single-censored samples. Biometrika, 52, 203.

GOUGH, K.R., BARDHAN, K.D., CROWE, J.P., KORMAN, M.G., LEE, F.I., REED, P.I. \& SMITH, R.N. (1984). Ranitidine and cimetidine in prevention of duodenal ulcer relapse. Lancet, ii, 659.

GRAY, G.R., McWHINNIE, D., SMITH, I.S. \& GILLESPIE, G. (1982). Five-year study of cimetidine or surgery for severe duodenal ulcer dyspepsia. Lancet, i, 787.

KRATOCHVIL, P. \& BRANDSTÄTTER, G. (1983). Ergebrisse einer zweijährigen Langzeitprophylaxe des Ulcus duodeni mit Cimetidin. Medwelt, 34, 1380.

MCCARTHY, D.M. (1984). Smoking and ulcers - time to quit. New England Journal of Medicine, 311, 726.

MISIEWICZ, J.J. \& BRADBURY, J.E. (1984). Review of trials of maintenance treatment for the prevention of duodenal ulcer recurrence. In Ranitidine: Therapeutic Advances, Misiewicz, J.J. \& Wood, J.R. (eds). p.43. Excerpta Medica: Amsterdam.

SCHUTZ, E. (1985). Langzeiter fahrungen mit dem neuen $\mathrm{H}_{2}$ Blocker Ranitidin bei Patienten mit chronischer Ulcus duodeni-Erkrankung. Kassenarzt, 23, 46.

SONTAG, S., GRAHAM, D.Y., BELSITO, A. and members of Study Group (1984). Cimetidine, cigarette smoking, and recurrence of duodenal ulcer. New England Journal Medicine, 311, 689.

STROM, M., BODEMAR, G., LINDHAGEN, J., SJÖHDAHL R. \& WALAN, A. (1984). Cimetidine or parietal-cell vagotomy in patients with juxtapyloric ulcers. Lancet, ii, 894.

WALAN, A., BIANCHI PORRO, G. \& HENTSCHEL, E. (1985). Maintenance cimetidine for up to three years. Lancet, $i$, 115. 